\title{
Use of Benzoctamine as Sedative in Patients with Respiratory Failure
}

\author{
T. J. H. CLARK, J. V. COLLINS
}

British Medical fournal, 1973, 1, 75-76

ASTHMA

\section{Summary}

Benzoctamine (Tacitin) was given by mouth as night sedation to patients admitted to hospital with respiratory failure. Fourteen patients had chronic obstructive bronchitis and six had acute severe asthma. One patient with asthma needed intravenous sedation with benzoctamine. No adverse effects were observed, and there was no significant change of forced expiratory volume in one second $\left(\mathrm{FEV}_{1}\right)$, forced vital capacity (FVC), or $\mathrm{PCO}_{2}$ in any patient after benzoctamine. Nevertheless, further clinical experience of the drug is required before its use can be safely recommended in respiratory failure.

\section{Introduction}

The risks of sedation in patients with respiratory failure are well known, and it appears that there is no drug with sedative, hypnotic, or tranquillizing properties which can be given with safety to these patients (Clark, Collins, and Tong, 1971). This is unfortunate as there are many occasions when such treatment is desirable, and the statement that benzoctamine (Tacitin) when used as a tranquillizer does not cause respiratory depression (Geisler and Rost, 1970) excited our interest. We have set out to examine this claim by giving benzoctamine to patients with respiratory failure.

\section{Patients and Methods}

Altogether, 20 patients were studied on 23 admissions to hospital (12 men, mean age 63.6 years, and eight women, mean age 42.4 years). Fourteen were in respiratory failure secondary to chronic obstructive bronchitis and six had acute exacerbation of bronchial asthma. On 15 admissions the patient was given $10 \mathrm{mg}$ (one tablet) of benzoctamine and on eight admissions $20 \mathrm{mg}$ were given.

\section{CHRONIC OBSTRUCTIVE BRONCHITIS}

Seven patients with chronic obstructive bronchitis were studied during the first 24 hours of 10 admissions to hospital with acute on chronic respiratory failure. On six occasions the patient was given $10 \mathrm{mg}$ of benzoctamine and on four occasions $20 \mathrm{mg}$ were given.

On eight other occasions seven patients with chronic respiratory failure associated with chronic obstructive bronchitis were given benzoctamine during the recovery phase after an admission for acute exacerbation of symptoms. In this group $10 \mathrm{mg}$ benzoctamine was prescribed on six occasions and $20 \mathrm{mg}$ on the remaining two occasions.

Benzoctamine tablets were given to all except one woman (Case 7) with asthma who is discussed separately. All patients with asthma were studied during the first 24 hours after admission to hospital with an acute attack of severe asthma. Two patients were given $10 \mathrm{mg}$ of benzoctamine and three patients were given $20 \mathrm{mg}$.

\section{STUDY}

Forced expiratory volume in one second $\left(\mathrm{FEV}_{1}\right)$ and forced vital capacity (FVC) were measured with a Vitalograph dry spirometer and peak expiratory flow rate (PEFR) was measured with a Wright peak flow meter. These measurements were made in all patients. Arterial blood samples were obtained in four patients with chronic obstructive bronchitis and three patients with asthma, and $\mathrm{pH}$, oxygen, and carbon dioxide tensions were estimated using a Radiometer AMI machine. In all other studies mixed venous carbon dioxide tensions were estimated by using a rebreathing method (Campbell and Howell, 1962).

In all patients measurements were made in the evening before the administration of benzoctamine as night sedation and were repeated the next morning. In all patients benzoctamine was given only if the clinician responsible thought sedation a desirable course of treatment. In addition to the measurements made before benzoctamine and again the next morning, the clinical state of each patient was closely observed during the night.

\section{Results}

For purposes of simplicity in calculating values for carbon dioxide tension in each group of patients the results of mixed venous and arterial tensions have been grouped together. In the individual patient the same technique, arterial or rebreathing, was used before and after the administration of benzoctamine.

Preliminary analysis of the results showed that the effects of $10 \mathrm{mg}$ and $20 \mathrm{mg}$ benzoctamine were similar, and the results of both dose levels have been consolidated. The results for each group of patients are shown in the chart, and it can be seen that there was no rise in $\mathrm{PCO}_{2}$ after administration of 10 or $20 \mathrm{mg}$ of benzoctamine. In six patients arterial blood gas analysis was performed and the results are summarized in table $I$, which also shows that benzoctamine produced no consistent adverse effects on alveolar ventilation.

One woman (case 7) aged 50 years with severe asthma was agitated whenever awake, and this was associated with laboured breathing, loud wheezing, and a fall in arterial oxygen tension. She was given a total of $50 \mathrm{mg}$ benzoctamine in two intravenous injections at 20-minute intervals. This produced a restful sleep during which the wheezing diminished and her arterial oxygen tension rose without any change being made in the oxygen concentration in the inspired gas mixture (see table II).

In all instances observations were maintained during the night and no patient developed $\mathrm{CO}_{2}$ narcosis. Pulse and respiration rates remained stable, and all patients were rousable and woke normally the next morning. 

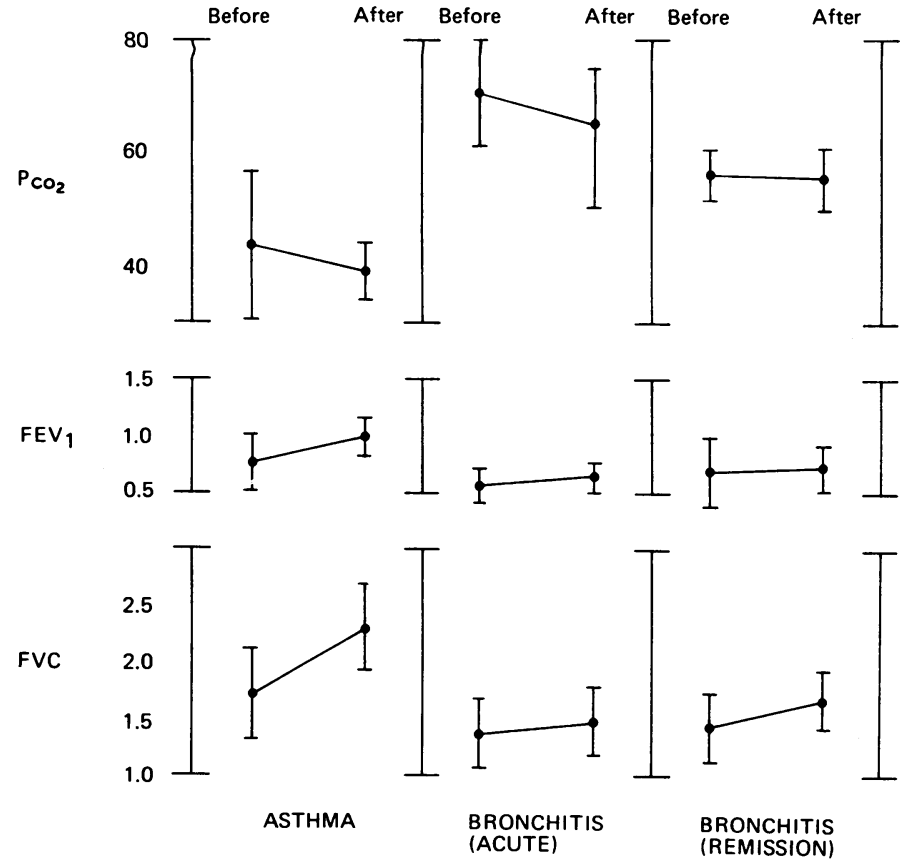

$\mathrm{PCO}_{2}, \mathrm{FEV}_{1}$, and FVC before and after benzoctamine in patients with asthma or chronic obstructive bronchitis. In each group results are given as mean \pm 1 S.D. Patients received 10 or $20 \mathrm{mg}$ benzoctamine.

TABLE I-Arterial Blood $\mathrm{pH}$ and Gas Tensions before and after Benzoctamine in Two Patients with Acute Bronchial Asthma and Four Patients with Acute on Chronic Respiratory Failure associated with Obstructive Bronchitis

\begin{tabular}{|c|c|c|c|c|c|c|c|c|c|}
\hline \multirow{2}{*}{$\begin{array}{l}\text { Case } \\
\text { No. }\end{array}$} & \multirow{2}{*}{ Sex } & \multirow{2}{*}{ Age } & \multirow{2}{*}{$\begin{array}{l}\text { Benzoctamine } \\
\text { Dose }\end{array}$} & \multicolumn{3}{|c|}{$\begin{array}{c}\text { Arterial Levels } \\
\text { Before }\end{array}$} & \multicolumn{3}{|c|}{$\begin{array}{l}\text { Arterial Levels } \\
\text { After }\end{array}$} \\
\hline & & & & $\mathrm{pH}$ & $\mathrm{PcO}_{2}$ & $\mathrm{Po}_{2}$ & $\mathrm{pH}$ & $\mathrm{PCO}_{2}$ & Po, \\
\hline \multicolumn{10}{|c|}{ Bronchitis } \\
\hline $\begin{array}{ll}1 & . \\
2 & \cdots \\
3 & \cdots \\
4 & \cdots\end{array}$ & $\begin{array}{l}\text { M. } \\
\text { M. } \\
\text { M. }\end{array}$ & $\begin{array}{l}69 \\
66 \\
64 \\
72\end{array}$ & $\begin{array}{l}20 \mathrm{mg} \\
20 \mathrm{mg} \\
10 \mathrm{mg} \\
10 \mathrm{mg}\end{array}$ & $\begin{array}{l}7.38 \\
7.37 \\
7.44 \\
7.27\end{array}$ & $\begin{array}{l}66 \\
67 \\
54 \\
85\end{array}$ & $\begin{array}{l}37 \\
40 \\
42 \\
30\end{array}$ & $\begin{array}{l}7 \cdot 40 \\
7 \cdot 49 \\
7 \cdot 40 \\
7 \cdot 42\end{array}$ & $\begin{array}{l}68 \\
57 \\
49 \\
60\end{array}$ & $\begin{array}{l}55 \\
40 \\
40 \\
44\end{array}$ \\
\hline $\begin{array}{ll}5 & \ldots \\
6 & \ldots\end{array}$ & $\begin{array}{l}\text { F. } \\
\text { F. }\end{array}$ & $\begin{array}{l}56 \\
22\end{array}$ & $\begin{array}{l}10 \mathrm{mg} \\
20 \mathrm{mg}\end{array}$ & $\begin{array}{c}\text { sthma } \\
7 \cdot 42 \\
7 \cdot 26\end{array}$ & $\begin{array}{l}46 \\
64\end{array}$ & $\begin{array}{l}70 \\
60\end{array}$ & $\begin{array}{l}7 \cdot 44 \\
7 \cdot 37\end{array}$ & $\begin{array}{l}32 \\
42\end{array}$ & $\begin{array}{l}56 \\
60\end{array}$ \\
\hline
\end{tabular}

TABLE II-Arterial Blood $p H$ and Gas Tensions before and after $50 \mathrm{mg}$ Intravenous Benzoctamine in a Patient with Acute Asthma (Case 7) (Breathing Oxygen by Mask)

\begin{tabular}{l|c|c|c}
\hline & \multicolumn{3}{|c}{ Arterial Levels } \\
\cline { 2 - 4 } & $\mathrm{pH}$ & PcO $_{\mathbf{2}}$ & Po, $_{2}$ \\
\hline $\begin{array}{l}\text { Before benzoctamine, awake } \\
\text { After benzoctamine, asleep }\end{array}$ & $\mathbf{7 \cdot 4 4}$ & $\mathbf{4 6}$ & 46 \\
\hline
\end{tabular}

\section{Discussion}

Preliminary studies (Rondel, 1972) have shown that benzoctamine could be given intravenously with safety to patients with chronic respiratory failure. Five patients were studied with doses of 20-30 mg, and arterial blood gas analysis showed no change 20 minutes after injection. Other work also showed that benzoctamine did not reduce the $\mathrm{CO}_{2}$ responsiveness but rather caused an increased ventilatory response to $\mathrm{CO}_{2}$ (Geisler and
Rost, 1970). The present study set out to extend these observations in a more realistic clinical setting. The major risk of sedatives lies in the respiratory depression that occurs in patients with acute on chronic respiratory failure (Wilson et al., 1954; Sadoul, 1965). Our main purpose was to study the effect of benzoctamine in this situation but we have extended our observations to include patients with $\mathrm{CO}_{2}$ retention on recovery from an acute episode as well as patients with acute, severe asthma.

We felt it was not justified to extend the acute parenteral studies in these groups of patients but to observe closely the effect of benzoctamine when given in a conventional manner to patients thought to require sedation. We therefore only measured $\mathrm{PCO}_{2}$ and other physiological variables before drug administration and again the next morning as this should have been sufficient to document the clinical diagnosis of $\mathrm{CO}_{2}$ narcosis, which usually appears within hours of sedation and lasts many hours even if intervention is prompt. No patient developed $\mathrm{CO}_{2}$ narcosis and no evidence for a more insidious worsening of gas exchange was found.

In summary, our initial experience with benzoctamine has been promising when used in a realistic clinical setting. In two of the patients who were very anxious and distressed by dyspnoea a dose of 40-50 mg of benzoctamine three times a day by mouth produced satisfactory clinical benefit without respiratory depression. In case 7 the benefits of sedation were clearly seen both clinically and in terms of blood gas tensions. If further experience with benzoctamine confirms its safety in these patients the place for sedation in respiratory failure should be reviewed.

No simple explanation can be given for the apparent safety of the drug in patients with respiratory failure. It is of interest that tricyclic antidepressants rarely cause respiratory depression, and we note that benzoctamine bears some resemblance to this group of drugs. Our findings may be partly explained by an earlier report in which benzoctamine had been shown to stimulate respiration in some subjects (Geisler and Rost, 1970). These findings await confirmation by further studies of the effects of this drug on $\mathrm{CO}_{2}$ responsiveness.

Only more extensive clinical experience will show the degree of safety provided by benzoctamine when given as a hypnotic or sedative in patients with respiratory failure.

We should like to thank Dr. R. K. Rondel at CIBA Laboratories for advice and help. Our thanks are also due to our colleagues who allowed us to study patients under their care.

Requests for reprints should be addressed to: Dr. T. J. H. Clark, Guy's Hospital, London SE1 9RT.

\section{References}

Campbell, E. J. M., and Howell, J. B. L. (1962). British Medical fournal,

2, 630. Geisler, L., and Rost, H.-D. (1970). Proceedings of International Symposium on Anxiety and Tension-New Therapeutic Aspects. St. Moritz. p. 57.

Rondel, R. K. (1972). Clinical Research Department CIBA/Geigy, Basle. File data, available on request.

Sadoul, P. (1965). Annals of the New York Academy of Sciences, 121, 836.

Wilson, R. H., Hoseth, W., and Dempsey, M. E. (1954). American fournal of Medicine, 17, 464. 